\title{
The Role of Low Risk Drinking in the Treatment of Alcohol Problems: A Commentary
}

\author{
M.B. Sobell L.C. Sobell \\ Nova Southeastern University, Fort Lauderdale, FL, USA
}

\section{Key Words}

Alcohol problems - Low risk drinking · Treatment . Moderation · Problem drinking

\section{Summary \\ The majority of individuals with alcohol-related prob- lems, often referred to as problem drinkers, have prob- lems that are not severe. Although brief outpatient inter- ventions have been shown to be efficacious for problem drinkers, appropriate services are lacking because most existing treatments were developed for more severely dependent alcohol abusers. Problem drinkers view tradi- tional treatments as overly intensive and as having an unnecessary requirement of abstinence. Furthermore, the confrontational nature of the treatment elicits resis- tance. An alternative service delivery model, stepped care, emphasizes identifying and offering relevant ser- vices to problem drinkers in primary health care settings. Providing relevant services for problem drinkers could have considerable public health benefits.}

\section{Introduction}

While the estimated costs of alcohol-related problems are vast [National Institute on Alcohol Abuse and Alcoholism, 2000], the majority of such costs stem from individuals who have been labeled 'problem drinkers' [Cahalan, 1987b; Institute of

\section{Schlüsselwörter}

Alkoholprobleme · Alkoholkonsum, mäßiger .

Behandlung · Moderation · Problemtrinken

\section{Zusammenfassung}

Der Einfluss von mäßigem Alkoholkonsum auf die Behandlung von Alkoholmissbrauch: Ein Kommentar

Bei der Mehrzahl der Menschen mit alkoholbedingten Problemen, die häufig als "Problemtrinker" bezeichnet werden, sind diese Schwierigkeiten nicht gravierend. Obwohl sich ambulante Kurzinterventionen bei Problemtrinkern als wirksam erwiesen haben, fehlen entsprechende Anlaufstellen in der Gesundheitsfürsorge, denn die meisten Behandlungskonzepte wurden für schwerer erkrankte, abhängige Trinker entwickelt. Problemtrinker betrachten diese herkömmlichen Behandlungsansätze als zu intensiv und als unnötigerweise mit einem Abstinenzgebot verknüpft. Darüber hinaus ruft das konfrontative Vorgehen dieser Ansätze Widerstand hervor. Ein alternatives, gestuftes Behandlungsmodell stellt dagegen passende Angebote für Problemtrinker in der medizinischen Grundversorgung in den Mittelpunkt. Die Bereitstellung passender Angebote für Problemtrinker könnte erhebliche positive Auswirkungen auf die öffentliche Gesundheitsfürsorge haben.
Medicine, 1990; Kahan, 1996; Sobell and Sobell, 1993b]. As shown in table 1, problem drinkers differ from severely dependent alcohol abusers in many ways [Kahan, 1996; Sobell and Sobell, 1993a].

Although the differences between problem drinkers and severely dependent drinkers are evident to the practitioner

\begin{tabular}{ll}
\hline KARGER & @ 2004 S. Karger GmbH, Freiburg \\
$\begin{array}{l}\text { Fax +49 7614520714 } \\
\begin{array}{l}\text { E-mail Information@Karger.de } \\
\text { www.karger.com }\end{array}\end{array}$ & $\begin{array}{l}\text { Accessible online at: } \\
\text { www.karger.com/ver }\end{array}$ \\
&
\end{tabular}

Mark B. Sobell, PhD, ABPP

Center for Psychological Studies

Nova Southeastern University

3301 College Ave., Fort Lauderdale, Florida 33314

Tel. +1 954 262-5747, Fax +1 954 262-3895

E-mail sobellm@nsu.nova.edu 
Tab. 1. Differences between problem drinkers and severely dependent alcohol abusers*

\begin{tabular}{lll}
\hline Clinical feature & Problem drinkers & $\begin{array}{l}\text { Severely dependent } \\
\text { drinkers }\end{array}$ \\
\hline $\begin{array}{l}\text { History of major withdrawal symptoms (i.e., DTs, seizures, } \\
\text { hallucinations) }\end{array}$ & no & yes \\
$\begin{array}{l}\text { Amount of alcohol consumed per week } \\
\text { Drinks moderately (<4 drinks/day) }\end{array}$ & $>12$ drinks \\
Problem drinking history duration & often & $>60$ drinks \\
Social consequences related to alcohol use & short & rarely \\
Socially stable & none or mild & long \\
Physical consequences related to alcohol use & usually & often severe \\
Neglects major responsibilities (e.g., work, family) & none or mild & often not \\
Identifies with 'alcoholic' label & typically no & often severe \\
Post-treatment outcomes, including moderate drinking & no & yes \\
$\begin{array}{l}\text { Past history of alcohol treatment } \\
\text { Reluctant to enter traditional alcohol treatment programs }\end{array}$ & very good & many never in treatment \\
Views inpatient/residential treatment as too demanding & yes & poor \\
Would prefer moderate drinking rather than an abstinence & yes & yes \\
$\quad$ goal & & no \\
In a motivational conflict (i.e., ambivalent about changing as & yes & no \\
$\quad$ drinking has caused few problems) & typically yes & no \\
\hline
\end{tabular}

a 1 Drink $=14 \mathrm{~g}$ of absolute ethanol.

*Reprinted with permission from: Sobell LC, Sobell MB: Using motivational interviewing techniques to talk with clients about their alcohol use. Cog Behav Pract, in press. Original table adapted from: Kahan M: Identifying and managing problem drinkers. Can Fam Physician 1996;42:661-671. when conducting a clinical assessment, formal diagnostic classifications are of little help because most problem drinkers meet diagnostic criteria for alcohol dependence. Nevertheless, problem drinkers generally have experienced fewer alcoholrelated consequences (e.g., social, legal, health) and have more intact social and economic resources than severely dependent individuals. Because some of their drinking is at low risk levels, an important difference is that they often do not view their drinking as problematic [Sobell and Sobell, 1993a]. Consequently, treatment approaches that attempt to convince problem drinkers that they cannot reliably limit their drinking lack credibility. Because they do not fit the traditional stereotype of an 'alcoholic,' problem drinkers resist being labeled 'alcoholic' [Sobell and Sobell, 2003]. Thus, they often find themselves in conflict about whether their drinking is a problem. Finally, the absence of physiological dependence may be a useful way of distinguishing between problem drinkers and those generally viewed by society as 'alcoholics.' Schuckit et al. [2003] conducted a large prospective study of individuals who had an alcohol dependence diagnosis with and without a physiological component and found that the presence of physiological dependence predicted a more severe clinical course. In summary, there are substantial differences between problem drinkers and severely dependent alcohol abusers.

Related to less severe alcohol problem histories and a lack of physical dependence, problem drinkers have different treatment needs from severely dependent alcohol abusers. This issue was discussed by the Institute of Medicine (IOM) over a decade ago, which noted that although it is estimated that there are about four problem drinkers for every one severely dependent drinker, nearly all treatment programs were designed for severely dependent alcohol abusers [Institute of Medicine, 1990]. For example, although a National Treatment Center Study found that $93.1 \%$ of 450 private-sector alcohol and chemical dependency treatment programs in the US reported using a 12-step model [Peele, 1998], most problem drinkers respond well to brief interventions aimed at helping them reduce rather than stop their drinking [Babor et al., 1994; Heather, 2002; Miller and Wilbourne, 2002; Sobell and Sobell, 1995].

An alternative approach to offering services for problems drinkers involves using primary health care settings [Fleming and Manwell, 1999]. Such an approach has several advantages: (a) problem drinkers are unlikely to enter traditional treatment programs [Institute of Medicine, 1990], (b) they are seen frequently in primary care settings for other health problems [Kahan, 1996], (c) the vast majority of individuals including problem drinkers see a physician at least annually [National Center for Health Statistics, 2000], and (d) problem drinkers respond to brief interventions delivered in primary health care settings [Fleming and Manwell, 1999; Fleming et al., 1997]. The remainder of this article looks at the issue of providing services for problem drinkers using an alternative service delivery model. In this regard, the use of a low risk drinking goal as an alternative to abstinence for problem drinkers is an important issue in this discussion. 


\section{Low Risk Drinking and Treatment}

For close to half a century, the appropriateness of low risk drinking goals for some individuals with alcohol problems has been hotly debated [Marlatt, 1983; Pattison et al., 1977; Rosenberg, 1993; Sobell and Sobell, 1984]. Because low risk drinking is accepted as a treatment goal for problem drinkers in many countries outside of the United States [Rosenberg et al., 1996; Rosenberg et al., 1992], the present discussion will focus on issues in the US. First, however, low risk drinking needs to be defined.

Although several definitions of low risk drinking exist, they all embody limits that epidemiological research suggests are not linked to health risks. The most conservative limits recommend no more than one drink (approximately $14 \mathrm{~g}$ ethanol in the US; International Center for Alcohol Policies, 1998] per day for women and no more than two drinks per day for men [National Institute on Alcohol Abuse and Alcoholism, 1992]. Canada [Addiction Research Foundation and Canadian Centre on Substance Abuse, 1993] and Great Britain [Royal College of Physicians, 1987] recommend no more than two drinks per day for men and somewhat less for women. An important and often unstated aspect of low risk drinking recommendations is that drinking should only occur in situations where there is little or no chance of experiencing adverse consequences [Sobell and Sobell, 1993a].

Because there is compelling evidence that when problem drinkers have successful treatment outcomes (usually assessed as either no drinking or drinking below levels considered to incur health risks, plus no evidence of negative consequences related to drinking) they most often have reduced rather than stopped their drinking [Sobell and Sobell, 1995], it can be argued that low risk drinking should be considered when providing services for problem drinkers. Unfortunately, few treatment programs in the US allow clients to choose a low risk drinking goal [Rosenberg and Davis, 1994]. To understand this contradiction, it is necessary to discuss the concept of progressivity.

\section{Alcohol Problems and Progressivity}

Although the idea that alcohol problems are progressive is an accepted and reified component of the 12-step treatment approach [Nowinski et al., 1992], empirical studies repeatedly contradict progressivity. The concept of progressivity, first proposed by Jellinek more than 50 years ago [Jellinek, 1946], was based on questionnaires completed by a small number of Alcoholics Anonymous (AA) members. Jellinek rank ordered the reported onset of symptoms and, not surprisingly, found that less severe symptoms (e.g., hangovers, feeling guilty) preceded more severe symptoms (e.g., withdrawals). While this ordering was presented as evidence of progressivity, the appropriate method for evaluating progressivity is to prospectively study the phenomenon and evaluate whether those who have less severe symptoms develop more severe symptoms in the absence of an intervention.
Three decades of research involving several longitudinal studies demonstrate that the development of alcohol problems is not progressive [reviewed in Finney et al., 1999; Pattison et al., 1977]. The most typical pattern has been described as moving into and out of periods of alcohol problems of varying severity [Cahalan, 1987a, b; Cahalan and Room, 1974]. These problem periods are separated by periods of abstinence or low risk drinking. Dawson [1996], for example, found that many individuals who were diagnosed as alcohol dependent at one time either met the diagnosis for alcohol abuse (less severe problem) or had no diagnosis at a later time. Another recent longitudinal study tracked individuals who met diagnostic criteria for alcohol abuse and concluded that 'DSM-IV alcohol abuse predicts a less persistent, milder disorder that does not usually progress to dependence' [Schuckit et al., 2001]. This latter study is important to the present discussion because it suggests that low-level problems will not necessarily worsen even if the individual continues to use alcohol. A not unexpected exception to the lack of progressivity is that once problems become very serious the likelihood of them worsening increases without treatment [Fillmore and Midanik, 1984]. In summary, for most individuals, especially those with less severe problems, alcohol problems are not progressive.

Although the lack of empirical support for progressivity has existed for years [Pattison et al., 1977], in the US the concept of progressivity has been the major obstacle to providing alternative services for problem drinkers [Sobell and Sobell, 1993b]. The argument has been that where individuals fall on the progressivity continuum is irrelevant, because if they continue to drink their alcohol problem will continue to worsen. Consequently, abstinence has been viewed as the cornerstone of treatment for anyone with an alcohol problem.

\section{Alternative Services for Problem Drinkers}

There are several reasons why problem drinkers need different services than those for severely dependent drinkers. First, problem drinkers' lives (e.g., family, job) typically have not been severely impacted by their drinking, and in some cases, they may not have experienced any consequences. Therefore, many problem drinkers do not view their drinking as that serious [Sobell and Sobell, 1993a]. Importantly, they are reluctant to enter traditional intensive treatments as they require a significant time commitment or lifestyle change (e.g., permanent abstinence).

Another reason for offering alternative treatments for problem drinkers is because traditional programs are confrontational [Nowinski et al., 1992; Substance Abuse and Mental Health Administration, 1999]. Traditional programs assume drinkers are in 'denial' and that to make progress drinkers need to overcome their denial and recognize that they are 'alcoholic' and can never drink again [Saunders and Wilkinson, 1990]. Research, however, has found that a confrontational approach results in significantly greater attrition from treatment for problem drinkers [Miller et al., 1993; Pomerleau et 
al., 1976; Substance Abuse and Mental Health Administration, 1999]. Confrontational approaches also (a) produce more drinking by patients during treatment, (b) evoke more resistance the more confrontive the therapist, and (c) lead to poorer treatment outcomes [Miller et al., 1993].

The last reason why problem drinkers need alternative interventions is because, as mentioned earlier, most will seek to reduce rather than stop their drinking, regardless of what they are told in treatment [reviewed in Sobell and Sobell, 1995]. Further, the majority of problem drinkers who achieve positive outcomes after treatment reduce rather than stop their drinking [Sobell and Sobell, 1995]. Thus, for problem drinkers to accept an intervention, it needs to incorporate goal flexibility. Such an approach is used in several countries outside the US where physicians are encouraged to identify patients who drink above risk levels and counsel them to reduce their drinking [Anderson and Scott, 1992; Babor et al., 1994; Kahan et al., 1995; Saunders and Foulds, 1992]. To a lesser extent this approach has been used in the US [Fleming and Manwell, 1999].

\section{Would Problem Drinkers Be at Risk?}

One concern about using low risk drinking goals is that problem drinkers might use a reduced drinking goal to rationalize continued heavy drinking. Clearly, misuse of the approach is a risk that should be considered when evaluating treatment options, but risk is not a new concept in health care. In fact, risk is associated with other types of treatments (e.g., cancer, laser eye surgery, experimental drugs). The issue is whether the risk is justified (i.e., What alternative interventions are available and how effective are they? Do patients find them acceptable?). From a public health perspective, acceptability to patients is important. Although the best way to avoid further alcohol problems might be to stop drinking, one cannot ignore those who will not follow this advice.

\section{Low Risk Drinking Goals as Part of a Stepped Care Intervention}

Before proceeding, it is important to recognize that use of low risk drinking goals is not a harm reduction strategy. Rather, a harm reduction approach could be used for individuals who have severe drinking problems but are not willing to stop drinking. Such an approach involves using strategies to minimize the consequences of drinking for the individual and society, while keeping the individual in contact with services and encouraging reconsideration of a long-term abstinence goal [Larimer et al., 1998]. However, just as clients in abstinence programs often have an improved outcome rather than complete abstinence [Finney and Moos, 1991; Breslin et al., 1997] in some cases the outcome of using a low risk drinking goal can be better described as harm reduction or improvement. That is, the person's drinking is substantially reduced but still above levels suggested to be low risk. In fact, in many studies the main outcome reported is overall reduction in drinking [e.g., Fleming and Manwell, 1999] which makes it impossible to determine how many individuals would meet an absolute criterion for low risk drinking. That many outcomes may involve improvement rather than the absence of risk or problems is an important observation, but it does not detract from the contention that low risk drinking should be available as a goal for problem drinkers. It also is not relevant to the argument that offering nonabstinence alternatives will attract more problem drinkers to treatment.

If low risk drinking goals are to become a part of alcohol services, their integration into a system of care is critical. A stepped care system can accommodate low risk drinking goals. In a stepped care model, treatment is a dynamic process. The first treatment of choice is determined based on the research literature, clinical judgment, available resources, and the patient's wishes. Within those constraints, the treatment of choice is individualized, consistent with the contemporary research literature, and least restrictive, but still likely to work [Sobell and Sobell, 2000]. Once the initial treatment is implemented, a patient's progress is monitored and further treatment decisions are performance-based (i.e., depend on whether and at what rate the patient is improving). A lack of progress or a worsening requires that the treatment be modified by changing its intensity (e.g., more frequent sessions, residential versus outpatient) or selecting a different approach. In this sense, the process is self-correcting. For example, patients who choose a low-risk drinking goal but have difficulty reducing their drinking would be engaged in an informed dialogue about obstacles to change and whether abstinence would be a more reasonable goal. It is not uncommon for some individuals who initially choose a reduced drinking goal to switch to an abstinence goal [Miller and Page, 1991].

Unfortunately, a stepped care service delivery model is not currently used by substance abuse programs in the US. However, because of continuing health care accountability and cost containment priorities, substance abuse services will increasingly be held accountable for the same level of quality control as other health care services.

A stepped care approach suggests that identifying problem drinkers in primary healthcare settings would be a good first step toward helping them reduce or stop their drinking and would be accompanied by a lowered risk for many medical problems. In summary, while there are several compelling reasons why primary health care settings should be used to identify and treat problem drinkers, to do so successfully requires offering low risk drinking alternatives.

\section{Conclusions}

This article has reviewed four important reasons why low risk drinking goals for problem drinkers should be considered by primary health care providers: (a) the majority of alcohol abusers do not have severe drinking problems; (b) consider- 
able research shows that alcohol problems are not progressive; (c) most problem drinkers will seek to reduce rather than stop drinking, and when they have positive outcomes it most often is because they have moderated rather than quit drinking; and (d) because many people, including many problem drinkers, are seen in primary health care settings, offering brief interventions in such settings could yield considerable public health benefits as well as providing alternative and relevant services for individuals whose alcohol problems are not severe.

\section{References}

Addiction Research Foundation and Canadian Centre on Substance Abuse (ed): Moderate Drinking and Health. Paper presented at the International Symposium on Moderate Drinking and Health, Toronto, 1993.

Anderson P, Scott E: The effect of general practitioners' advice to heavy drinking men. Br J Addict 1992; 87:891-900.

Babor TF, Grant M, Acuda W, Burns FH, Campillo C, Del Boca FK, Hodgson R, Ivanets NN, Lukomskya M, Machona M, Rollnick S, Resnick R, Saunders JB, Skutle A, Connor R, Ernberg G, Kranzler H, Lauerman R, McRee B: A randomized clinical trial of brief interventions in primary health care: Summary of a WHO project. Addiction 1994;89:657-660.

Breslin FC, Sobell SL, Sobell LC, Sobell MB: Alcohol treatment outcome methodology: State of the art 1989-1993. Addict Behav 1997;22:145-155.

Cahalan D: Studying drinking problems rather than alcoholism; in Galanter M (ed): Recent Developments in Alcoholism, vol. 5. New York, Plenum, 1987a, pp 363-372.

Cahalan D: Understanding America's Drinking Problem: How to Combat the Hazards of Alcohol. San Francisco, CA, Jossey-Bass, 1987b.

Cahalan D, Room R: Problem Drinking among American Men. New Brunswick, NJ, Rutgers Center of Alcohol Studies, 1974

Dawson DA: Correlates of past-year status among treated and untreated persons with former alcohol dependence: United States, 1992. Alcohol Clin Exp Res 1996;20:771-779.

Fillmore KM, Midanik L: Chronicity of drinking problems among men: A longitudinal study. J Stud Alcohol 1984:45:228-236.

Finney JW, Moos RH: The long-term course of treated alcoholism: I. Mortality, relapse and remission rates and comparisons with community controls. J Stud Alcohol 1991;51:44-54.

Finney JW, Moos RH, Timko C: The course of treated and untreated substance use disorders remission and resolution, relapse and mortality; in McCrady BS, Epstein EE (eds): Addictions. A Comprehensive Guidebook. New York, Oxford University Press, 1999, pp 30-49.

Fleming M, Manwell LB: Brief intervention in primary care settings: A primary treatment method for at-risk, problem, and dependent drinkers. Alc Health Res World 1999;23:128-137.

Fleming MF, Barry KL, Manwell LB, Johnson K, London R: Brief physician advice for problem alcohol drinkers: A randomized controlled trial in communitybased primary care practices. J Am Med Assoc 1997; 227:1039-1045.

Heather N: Effectiveness of brief interventions proved beyond reasonable doubt. Addiction 2002;97:293-294.
Institute of Medicine (ed): Broadening the Base of Treatment for Alcohol Problems. Washington, DC, National Academy Press, 1990.

International Center for Alcohol Policies (ed): What is a 'Standard Drink'? Washington, DC, International Center for Alcohol Policies, Report 5, 1998.

Jellinek EM: Phases in the drinking histories of alcoholics. Q J Stud Alcohol 1946;7:1-88.

Kahan M: Identifying and managing problem drinkers. Can Fam Physician 1996;42:661-671.

Kahan M, Wilson L, Becker L: Effectiveness of physician-based interventions with problem drinkers: A review. Can Med Assoc J 1995;152:851-859.

Larimer ME, Marlatt GA, Baer JS, Quigley LA, Blume AW, Hawkins EH: Harm reduction for alcohol problems expanding access to and acceptability of prevention and treatment services; in Marlatt GA (ed): Harm Reduction: Pragmatic Strategies for Managing High-Risk Behaviors. New York, Guilford, 1998, pp 69-121.

Marlatt GA: The controlled drinking controversy: A commentary. Am Psychologist 1983;38:1097-1110.

Miller WR, Page AC: Warm turkey: Other routes to abstinence. J Subst Abuse Treat 1991;8:227-232.

Miller WR, Wilbourne PL: Mesa Grande: A methodological analysis of clinical trials of treatments for alcohol use disorders. Addiction 2002;97:265-277.

Miller WR, Benefield RG, Tonigan JS: Enhancing motivation for change in problem drinking: A controlled comparison of two therapist styles. J Consult Clin Psychol 1993;61:455-461.

National Center for Health Statistics (ed): Office visits to physicians. Hyattsville, MD, National Center for Health Statistics, 2000, Advance Data No. 322.

National Institute on Alcohol Abuse and Alcoholism (ed): Moderate drinking. Alcohol Alert, 16 PH, 1992, 315 , pp $1-4$.

National Institute on Alcohol Abuse and Alcoholism (ed): Tenth Special Report to the US Congress on Alcohol and Health. Washington, DC, US Government Printing Office, 2000

Nowinski J, Baker SC, Carroll K: Twelve Step Facilitation Therapy Manual (Project MATCH Monograph vol. 1). Rockville, MD, National Institute on Alcohol Abuse and Alcoholism, 1992.

Pattison EM, Sobell MB, Sobell LC: Emerging Concepts of Alcohol Dependence. New York, Springer, 1977.

Peele S: Ten radical things NIAAA research shows about alcoholism. Addictions Newsletter 1998;5,6:1719.

Pomerleau O, Pertschuk M, Stinnett J: A critical examination of some current assumptions in the treatment of alcoholism. J Stud Alcohol 1976;37:849-857.
Rosenberg H: Prediction of controlled drinking by alcoholics and problem drinkers. Psychol Bull 1993; 113:129-139.

Rosenberg H, Davis LA: Acceptance of moderate drinking by alcohol treatment services in the United States. J Stud Alcohol 1994;55:167-172.

Rosenberg H, Melville J Levell D, Hodge JE: A 10year follow-up survey of acceptability of controlled drinking in Britain. J Stud Alcohol 1992;53:441-446.

Rosenberg H, Devine EG, Rothrock N: Acceptance of moderate drinking by alcoholism treatment services in Canada. J Stud Alcohol 1996;57:559-562.

Royal College of Physicians (ed): The Medical Consequences of Alcohol Abuse: A Great and Growing Evil. London, Tavistock, 1987.

Saunders B, Wilkinson C: Motivation and addiction behaviour: A psychological perspective. Drug Alcohol Rev 1990;9:133-142.

Saunders JB, Foulds K: Brief and early intervention: Experience from studies of harmful drinking. Aust N Z J Med1992;22:224-230.

Schuckit MA, Smith TL, Danko GP, Bucholz KK, Reich T: Five-year clinical course associated with DSM-IV alcohol abuse or dependence in a large group of men and women. Am J Psychiatry 2001;158:10841090.

Schuckit MA, Danko GP, Smith TL, Hesselbrock V, Kramer J, Bucholz K: A 5-year prospective evaluation of DSM-IV alcohol dependence with and without a physiological component. Alcohol Clin Exp Res 2003; 27:818-825.

Sobell LC, Sobell MB: Using motivational interviewing techniques to talk with clients about their alcohol use. Cog Behav Pract 2003;10:214-221.

Sobell MB, Sobell LC: The aftermath of heresy: A response to Pendery et al.'s (1982) critique of 'Individualized behavior therapy for alcoholics'. Behav Res Ther 1984:22:413-440.

Sobell MB, Sobell LC: Problem Drinkers: Guided SelfChange Treatment. New York, Guilford Press, 1993a. Sobell MB, Sobell LC: Treatment for problem drinkers: A public health priority; in Baer JS, Marlatt GA, McMahon RJ (eds): Addictive Behaviors across the Lifespan: Prevention, Treatment, and Policy Issues. Beverly Hills, CA, Sage, 1993b, pp 138-157.

Sobell MB, Sobell LC: Controlled drinking after 25 years: How important was the great debate? Addiction 1995;90:1149-1153.

Sobell MB, Sobell LC: Stepped care as a heuristic approach to the treatment of alcohol problems. J Consult Clin Psychol 2000;68:573-579.

Substance Abuse and Mental Health Administration (ed): Enhancing motivation for change in substance abuse treatment (Treatment Improvement Protocol Series). Rockville, MD, US Department of Health and Human Services, 1999. 